\title{
Barriers and specifics preventing the global development of Slovak family enterprises in wood-working and furniture industry
}

\author{
Anna Kocianova ${ }^{1, *}$, Jarmila Schmidtova ${ }^{2}$, Maria $_{\text {Moresova }}{ }^{1}$, and Miroslava Melichova ${ }^{1}$ \\ ${ }^{1}$ Technical University in Zvolen, Faculty of Wood Sciences and Technology, Department of \\ Economics, Management and Business, T. G. Masaryka 24, 96001 Zvolen, Slovakia \\ ${ }^{2}$ Technical University in Zvolen, Faculty of Wood Sciences and Technology, Department of \\ Mathematics and Descriptive Geometry, T. G. Masaryka 24, 96001 Zvolen, Slovakia
}

\begin{abstract}
Research background: The worldwide importance of family business is evidenced by its more than seventy percent share in all enterprises. A survey in the field of family business in wood-working and furniture industry in Slovakia has not been carried out yet. The situation is not helped by the fact that the family business is not legally defined in the conditions of Slovak Republic.

Purpose of the article: The presented contribution tries to eliminate these shortcomings. Its goal is to map the situation of family wood-working and furniture enterprises in Slovakia as a hitherto unexplored segment to capture a view of their current position together with the main internal and external determinants hindering their development in practice and to approach the potential areas of future development of the businesses in question from their point of view.

Methods: The research method of the questionnaire survey was chosen.

Findings \& Value added: Based on the results of the survey, it can be stated that more than half of enterprises in wood-processing and furniture industry are family-owned and their main determinants of development can be considered lack of skilled labor and increasing intensity of competition with specific problems arising from the nature of family business which is underestimation of the issue of succession. The vision of the future development of these family businesses is to take advantage of the growing demand for organic products which they have at disposal.
\end{abstract}

Keywords: family business; furniture industry; global development; woodworking industry

JEL Classification: F14; F63; L20; L68; O14

${ }^{*}$ Corresponding author: xkocianovaa@,is.tuzvo.sk 


\section{Introduction}

The family business has a long tradition dating back to year 587, when the first Kongo Gumi family business (FB) was established in Japan. Since then, its importance has grown steadily and today FB worldwide account for 50-80\% of employment, more than two-thirds of GDP and their total number of enterprises exceeds 70\% (Family Firm Institute, 2016). Family businesses face, not only in Slovakia, weak legislative support. Definition of FB by law is absent in Slovakia, and therefore, based on its own survey from 2018, the Slovak Business Agency (SBA) defined it for domestic conditions as follows:

"Family business is a group of individual persons who have blood ties or court decisions or legally recognized ties with the same effect (adoption, marriage) or have personal, mutual ties and are interested in creating interdependence, interconnectedness and dependency through these common ties (mate, companion) and meet at least one of the following conditions in relation to the enterprise:

- one or more members own more than $50 \%$ of the shares or votes in enterprise,

- one or more members own in the enterprise such a share or number of votes that they are able to enforce their will against other co-owners (has influence),

- one or more members perform control functions in the enterprise and have influence,

- one or more members perform management functions in the enterprise and have influence.

According to the definition of FB by the European Commission, Slovakia, Cyprus and Estonia have the largest share of FB among EU member states. Pursuant to revised definition of FB for domestic conditions given above (compiled by the SBA), the share of FB in Slovakia is estimated at $60-80 \%$ in all sectors. Other data differ according to sources, which is due to differences in the definition of FB, as it is non-binding. FBs in Slovakia produce $30-40 \%$ of the value of GDP and account for $40 \%$ of employment (SBA, 2018). The data presented by the European National Association representing FB in EU (EFB, 2016) are even more favourable. The GDP indicator is estimated at $40 \%$ and employment at up to $60 \%$.

Furniture and wood-working industry, together with the pulp and paper industry, form a unified branch of the wood-processing industry (WPI) in Slovakia, which has a long tradition and untapped potential yet. This is reflected in its ecological direction and is supported by the increased interest in products that are environmentally friendly (which outputs of WPI are). Other predispositions are a rich domestic raw wood base, processing capacities (especially in the case of coniferous log), a stable share of the sector in the diversification of industry (approximately $2.5 \%$ over the decade). Long-term problems of the industry are the absence of support and development strategy, lack of targeted modernization of technology and technique, low attractiveness from the point of view of investors and entrepreneurs due to economic indicators, insufficient products finalization (value added), WPI enterprises act as subcontractors of semi-finished products for foreign enterprises and also the growth of competitiveness (Jelačić et al., 2012; Hajdúchová and Hlaváčková, 2019; Halaj et al., 2018). It follows that the WPI has enough space for future development and growth. At present, more than 5300 enterprises operate in this segment, which are based on the WPI tradition in Slovakia (Finstat, 2020). The level of forestry in Slovakia, which is at the level of $41.2 \%$ and has been growing exponentially over the years, also contributes to their prosperity (Hajdúchová and Hlaváčková, 2019).

The aim of the submitted contribution is to map the situation of family business in woodworking and furniture industry in Slovakia, as a hitherto unexplored segment, to define their current position together with a focus on the main internal and external determinants hindering their development in practice and then to approach potential areas of future development of these family businesses. 


\section{Methods}

Fulfilment of the set goal presupposes scientific work in the both level theoretical and also practical, as the form of obtaining primary data. As the theoretical basis showed, the definition of FB by law in Slovak conditions is absent. Therefore, the first step was to define the FB for the needs of this contribution. Research is based on the definition proposed by the SBA (2018), which reflects the needs and conditions in the domestic environment. An overview of FB abroad, its importance, basic features, specifics and problems, were processed on the basis of secondary sources by methods of analysis, description, comparison, analogy, summarization and synthesis. The relevant secondary sources were published surveys, studies, scientific and book publications, monographs, proceedings, laws and other relevant internet sources (especially statistics of a global, European and domestic nature produced by institutes, agencies or European Commission itself). Mapping the situation of family wood-working and furniture enterprises in practice presupposes the acquisition of primary data, for which a survey method in the form of an electronic questionnaire was used (Rimarčík, 2007; Pacáková, 2009). The final form of the questionnaire was created after piloting on a sample of 30 respondents. The questionnaire contained a total of 29 questions (closed and semi-closed with the answer type "other") due to the accuracy of the evaluation and the time-consuming completion. Its structure was compiled as follows: Introductory question (position of the respondent in the enterprise), Identification questions (district, level of operation, number of employees, years of operation, type of legal form, category of activity according to SK NACE classification of economic activities, distinction of family and nonfamily enterprises according to authoritative definition), Part of FB (external and internal problems, specific problems of FB, contribution of FB definition to practice, generational exchange, succession issues and its solution in practice), Part of non-family enterprises (internal and external problem factors for comparison with FB), Wood-processing industry (position of WPI in practice), Business development (areas of planned development). It is important to emphasize that despite the relatively long scope of the questionnaire, not all questions were asked to each respondent. It follows from the above that the questionnaire were divided into a total of 6 sections. Its succession was divided into sections family and non-family enterprises. The division consisted in identifying family and non-family enterprises as defined.

Based on data on all enterprises from Finstat (2020), it was possible to compile a database of contacts of WPI enterprises operating in Slovakia in a total of 5343. The questionnaire was sent to a total of 1500 enterprises for their e-mail contacts in September from the end of the year 2019 and a total of 209 completed questionnaires were obtained. The addressed enterprises were selected at random by drawing lots through a pseudo-random number generator. This ensured that each of the subjects had the same chance to choose (Faeron, 2017). In order to meet the condition for generalization of measured data and obtained results to the whole population of enterprises, it is necessary to meet the minimum sample size (n), which was determined by the following relationship to the calculation under conditions of permissible error of $5 \%(\mathrm{e}=0.05)$ and specified reliability $95 \%(\mathrm{z}=1.96)$ at known base set size $(\mathrm{N}=5343)$ and p-level 0.5 (Faeron, 2017):

$$
n=\frac{p \cdot(1-p)}{\frac{e^{2}}{z^{2}}+\frac{p \cdot(1-p)}{N}}
$$

The relationship thus defined for estimating the minimum sample size corresponds to 359 . At present, it is possible to work with answers from 209 enterprises. It follows that the findings can be claimed with a reliability of $85 \%$ and a materiality threshold of $15 \%$. Under such conditions, the sample size corresponds to a value of 200 that has been met. The results 
of the questionnaire survey were processed in the Statistica program and the following statistical methods were used to verify the assumed hypotheses: Exact binomial test (H1 and $\mathrm{H} 4)$ and Interval estimation of relative abundance ( $\mathrm{H} 2$ and $\mathrm{H} 3)$. Hypotheses assumed:

H1: It is assumed that at least half of Slovak wood-working and furniture enterprises are family-owned.

$\mathrm{H} 2$ : It is assumed that the main external problem in the development of wood-working and furniture enterprises is the intensity of the growth of competition from the perspective of other enterprises in the sector.

H3: It is assumed that the main internal problem of Slovak wood-working and furniture family enterprises is the lack of qualified workforce and disharmony of the interaction of family and business elements.

H4: It is assumed that most family wood-working and furniture enterprises in Slovakia do not have a developed succession strategy in a particular form.

The Exact binomial test is used to test a statistical hypothesis that the proportion of a certain value of a variable in the base set is equal to a given constant (Rimarčík, 2007). Hypothesis $\mathrm{H} 1$ was also verified by means of Interval estimation (together with $\mathrm{H} 2$ a H3) according to the relation for the calculation of the $95 \%$ Confidence interval for relative abundance:

$$
f-u_{\frac{\alpha}{2}} \sqrt{\frac{f(1-f)}{n}}<\varphi<f+u_{\frac{\alpha}{2}} \sqrt{\frac{f(1-f)}{n}}
$$

The Interval estimation of a parameter of the basic set parameter determines the numerical interval in which the estimated parameter is with a certain probability (i.e. the estimated parameter is in the interval $(\mathrm{q} 1, \mathrm{q} 2)$ with probability $1-\alpha)$. The interval $(\mathrm{q} 1, \mathrm{q} 2)$ is called the confidence interval and depends on $\alpha$ (Pacáková, 2009). The results of the survey were also processed by means of descriptive statistics and clear graphs were used for their simplicity, comprehensibility and graphical clarity to display of measured data.

\section{Results and Discussions}

The results of a survey of family wood-working and furniture enterprises in Slovakia evaluated by using selected statistical methods showed that their share within the industry reaches up to $60 \%$. This finding corresponds with the results of the SBA study (2018), which states that the share of FBs in all sectors is $60-80 \%$. FBs were selected on the basis of the definition given in the Introduction and this is in accordance with the conditions of the domestic business environment. A total of 129 FBs were distinguished from the sample. Exact binomial test using the value of p-level equal 0.000 confirm the validity of hypothesis $\mathrm{H} 1$, while the given hypothesis was also verified by means of Interval estimate for relative abundance with $95 \%$ confidence. This confirmed that $55.13 \%$ to $68.31 \%$ of Slovak woodworking and furniture enterprises can be considered as family businesses.

The family wood-working and furniture enterprises (FWFE) addressed in the survey identified the key determinants of business development from internal and external side of view. Priority is given to those they consider most important. The summary results are presented in Figure 1. The evaluation of the determinants shows that FWFE are most affected by the shortage of skilled workforce (73\%). The assumption from hypothesis H3 that main internal problem of Slovak FWFE is the lack of a qualified workforce has been confirmed. It is interesting to note that the second most common determinant that bothers FWFE in Slovakia is the rising costs of running a business $(51.3 \%)$. The determinant of competition was placed at $5^{\text {th }}$ place behind the lack of funds for the operation of the enterprise and supplier 
problems. However, this is not an inability to face competition, but a situation related to the growth of competing enterprises in the sector. Of the twelve evaluated determinants, the inability to face competition was ranked $10^{\text {th }}$. Under the given conditions, the hypothesis $\mathrm{H} 2$ can be confirmed.

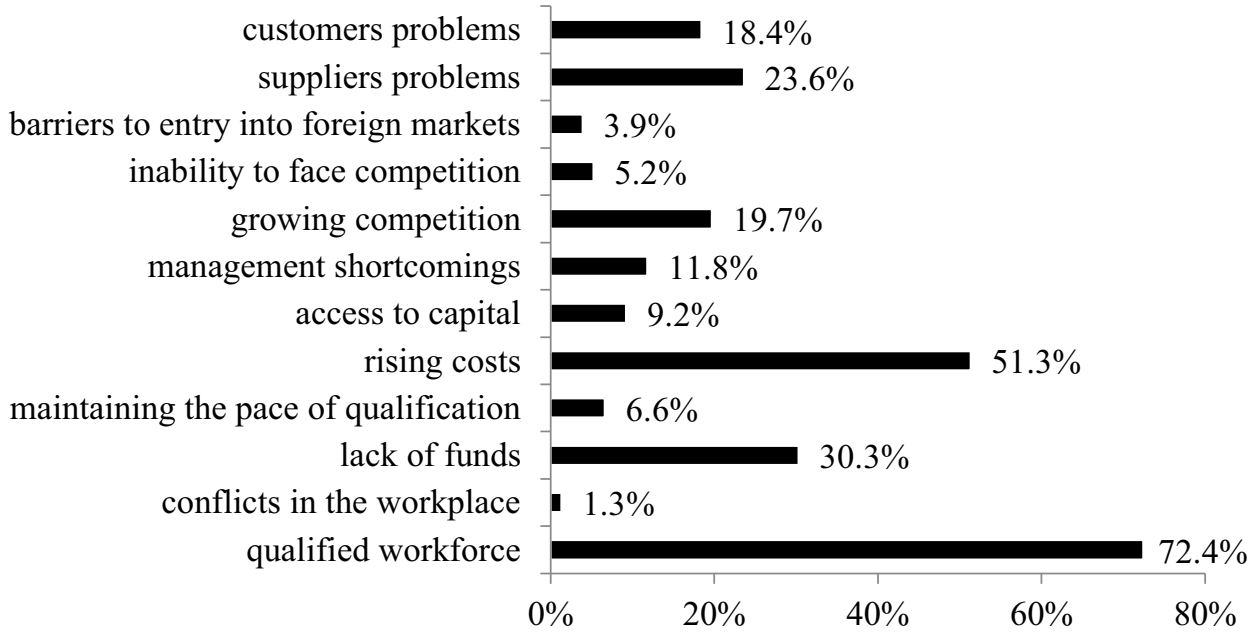

Figure 1. Internal and external determinants of family wood-working and furniture enterprises

Source: developed by the authors

At the same time, the survey also addressed the issue of general specific problems of FBs due to the assumption of its contribution to the issue of determinants of FWFE. The main one specific problems arising from the nature of FBs (Figure 2.) was the neglect of the family at the expense of the business $(56.5 \%)$.

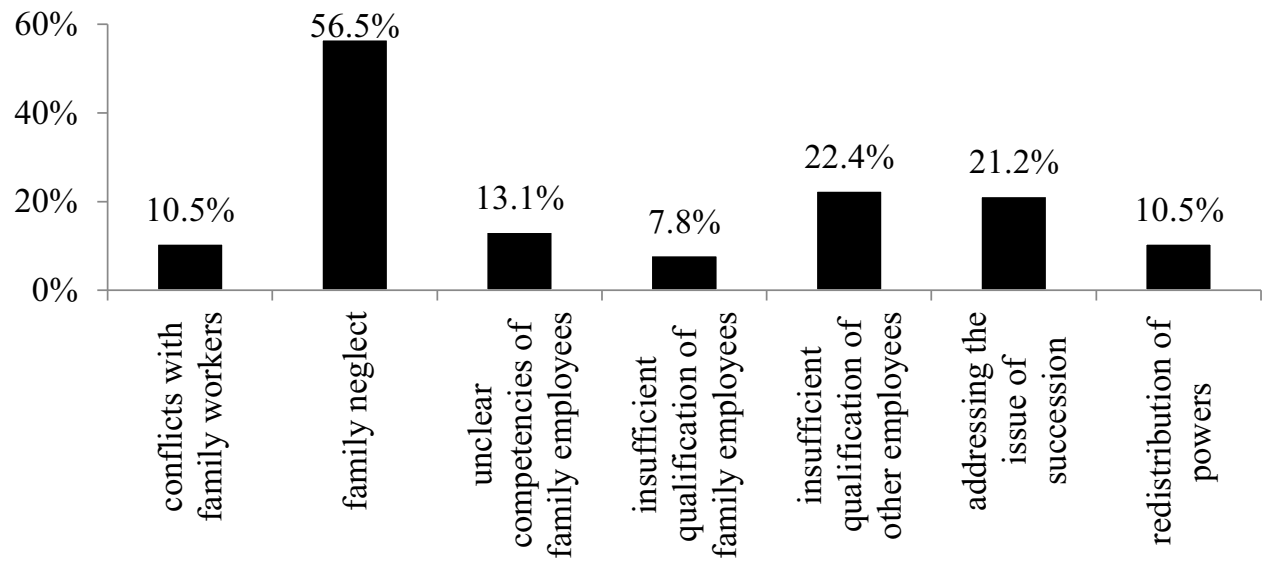

Figure 2. Specific determinants of family wood-working and furniture enterprises

Source: developed by the authors

As shown in Figure 2. a significant problem for the Slovak FWFE is also the topic of succession (21.2\%). As the Slovak FWFE started their activities after 1993 year, it is necessary to emphasize that most of them do not yet have experienced with the succession process. As reported by Szabó (2012) the succession process occurs approximately every 20- 
25 years and is managed by only about a third of enterprises. So far 28 years have passed since 1993 and the issue of succession is becoming one of the key priorities. The succession strategy will ensure a smooth transition of the enterprise to the next generation, but the results of the survey show that this area is highly undervalued and enterprises do not address it. As many as $90 \%$ of FWFE in Slovakia do not yet have a specific succession strategy and do not even address this topic. Of the $10 \%$ of respondents who resolved the issue of succession, two thirds transferred the enterprise to the direct descendant of the owner or another family member. The remaining third said that the enterprise would be sold or transferred to an external manager.

The survey also marginally addressed the issue of areas of development of FWFE to determine their future direction of expansion (Figure 3.). The most frequently mentioned areas in which FWFE anticipate development in descending order in the near future: technical equipment, technological process of production, quality of production and addressing new customers.

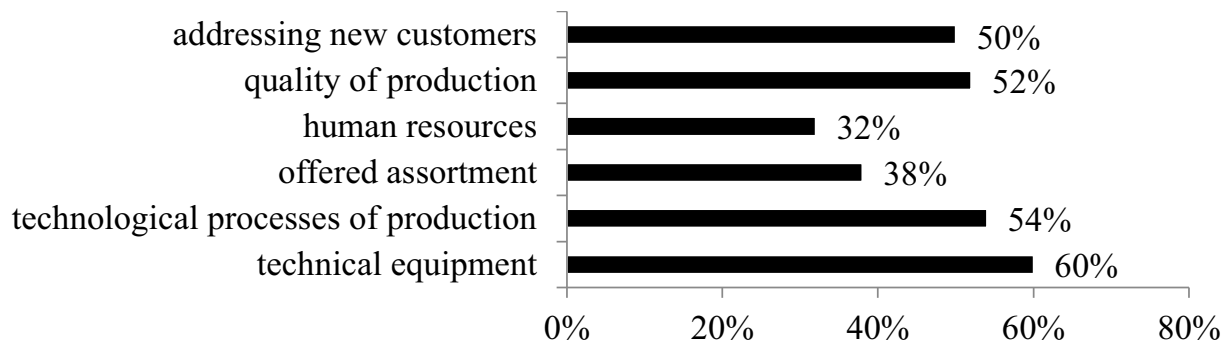

Figure 3. Intended areas of development of family wood-working and furniture enterprises

Source: developed by the authors

Family enterprises are characterized by their specifics in various areas as reported by Zhou (2014) and Ramadani et al. (2015). These specifics determine the positive or negative consequences for the enterprise. Authors Machek et al. (2014), Szabó (2012), Martin (2008), Wróblewska-Kazakin (2012) and many others agree that without the adoption of a specific definition of FB, at least at national (if not European) level, the collection and evaluation of data on this type of enterprises and its specific predispositions, problems and indicators cannot be simplified, thus not providing them with a specific and targeted form of assistance. Based on its own research into the issue of FB, the SBA submitted an estimate for the conditions of the Slovak business environment, which says that approximately $60-80 \%$ of enterprises in Slovakia in all sectors are family-owned. Specific research in the WPI with a link to a FB has not yet been published. By conducting a survey in this area, it was possible to confirm the assumption that most enterprises in the WPI are family-run. Every enterprise in a market economy is to some extent influenced by internal and external determinants of the business environment (Malá et al., 2017). It is also possible to speak of a group of factors that are partially variable (own activity or attitude towards them) such as competition, while the problem of the SME sector is relatively low competitiveness against large or other enterprises (SBA, 2018; Aymen et al., 2019; Sedliačiková et al., 2021). The group of factors creates, adjust and influenced itself is referred to as internal. A specific internal problem in the WPI is the provision of a qualified workforce, and therefore it can be assumed as problem of FB (Sedliačiková et al., 2020; Malá et al., 2017; Kovalčík, 2018). A particularly specific problem of FB is the achievement of harmony between family and work life for family members (Zhou, 2014), which was confirmed by the results of the research. In the area of determinants FWFE the results of survey confirmed the growing level of competition as the main external determinant and the lack of a qualified workforce as internal. Sustainability of 
FBs and the associated issue of succession is the biggest challenge (Szabó, 2012). Surveys show that only $16 \%$ of FBs have a formally established succession plan or even a selected suitable candidate for the position of successor in a FB (EFB, 2016). In this area, it is possible to confirm for the FWFE segment that they do not pay sufficient attention to the issue of succession. As many as $90 \%$ of them have not yet resolved the issue of succession or do not have a specific form of its strategy. The situation regarding ecological progress and the promotion of environmental protection has been felt in recent years. This creates space for WPI to use its ecological potential (use of renewable natural raw wood) to address especially environmentally conscious consumers to choose to buy products from the WPI which often meet a number of strict certification conditions (Gejdoš and Danihelová, 2015; Sharma and Joshi, 2017; Sachdeva et al., 2015; Malá et al., 2017). As part of FWFE it can be confirmed that such possibilities are open and can be considered as a vision of the future direction.

\section{Conclusions}

The aim of the contribution was to map the situation of FWFE, to clarify their current situation (the share of FBs in the WPI) with regard to defining the main internal and external determinants of their development and the specifics arising from the nature of FBs. At the same time, point out potential areas of future development of the enterprises in question. The set goals were achieved. Based on them, the following can be emphasized. More than half of the enterprises in the WPI in Slovakia are family enterprises. The main external determinant hindering their development is the intensity of competition growth. Lack of skilled workforce is considered to be the main internal determinant. In addition to the disharmony of the familybusiness relationship, a specific problem of FWFE is the neglect of the issue of succession. Also the vast majority of enterprises have not yet addressed the succession and have not even considered a suitable successor. Priority areas for future development include technical equipment, production technology, increasing the quality of production and reaching new customers. The vision of FWFE in Slovakia seems to be the use of the opportunity of ecological direction of the industry and the growth of demand for ecological products.

\section{Acknowledgements}

This research was funded by Slovak Research and Development Agency, grant number APVV-18-0520 and by Scientific Grant Agency VEGA, grant number VEGA 1/0161/21. Also by fund of KEGA project no. KEGA 005 TUZ-4/2020 and by fund of IPA project of Internal project agency project no. IPA 09/2021.

\section{References}

1. Aymen, A. Alhamzah, A., \& Bilal, E. (2019). A multi-level study of influence financial knowledge management small and medium enterprises. Polish Journal of Management Studies, 19(1), 21-31.

2. EFB. (2016). Fact \& Figures. http://www.europeanfamilybusinesses.eu/familybusinesses/facts-figures

3. Family Firm Institute. (2016). Global data points. http://www.ffi.org/page/globaldatapoints

4. Faoren, E. (2017). Sample Size Calculations for Population Size Estimation Studies Using Multiplier Methods with Respondent-Driven Sampling Surveys. JMIR Public Healts and Surveillance, 3(59), 59. 
5. Finstat. (2020). Všetky firmy a organizácie - databáza všetkých slovenských firiem a organizácii. https://finstat.sk/databaza-firiem-organizacii

6. Gejdoš, M., \& Danihelová, Z. (2015). Valuation and Timber Market in the Slovak Republic. International Scientific Conference: Business Economics and Management (BEM2015), 34, 697-703.

7. Hajdúchová, I., \& Hlaváčková, P. (2019). Impact of global economy of forestry and forest based industry in the Czech and Slovak Republic. Acta Facultatis Xylologiae, 56(2), 135-146.

8. Halaj, D., Sedliačiková, M., \& Malá, D. (2018). Customer Behavior on the Slovakian Roundwood Market: A Case Study. Bioresources, 13(3), 6003-6020.

9. Jelačić, D., Morom M., Drábek, J., \& Sujová, A. (2012). Motivation Factors in Wood Processin Plants. Wood Research, 57(2), 317-330.

10. Kovalčík, M. (2018). Efficiency of the Slovak forestry in comparison to other European countries:An application of Data Envelopment Analysis. Central European Forestry Journal, 64(1), 46-54.

11. Machek, O., Hnilica, J., \& Brabec, M. (2014). Current State of Knowledge on the Performance Gaps Between Family and Non-Family Firms. International Advances in Economic Research, 20(3), 349-350.

12. Malá, D., Sedliačiková, M., Dušak, M., Kaščáková, A., Musová, Z., \& Klementová, J. (2017). Green Logistics in the Context of Sustainable Development in Small and Medium Enterprises. Drvna industrija, 68(1), 69-79.

13. Malá, D., Sedliačiková, M., Kaščáková, A., Benčíková, D., Vavrová, K., \& Bikár, M. (2017). Green Logistics in Slovak Small and Medium Wood-Processing Enterprises. Bioresources, 12(3), 5155-5173.

14. Martin, R. (2008). Post-socialist segmented capitalism: The case of Hungary. Developing business systems theory. Human Relations, 61(1), 131-159.

15. Pacáková, V. (2009). Štatistické metódy pre ekonómov. WoltersKluwer.

16. Ramadani, V., \& Hoy., F. (2015). Context and Uniqueness of Family Businesses. Springer, Cham.

17. Rimarčík, M. (2007). Štatistika pre prax. Bratislava: Marián Rimarčík.

18. Sachdeva, S., Jordan, J., \& Mazar, N. (2015). Green consumerism : moral motivations to a sustainable future. Current opinion in Psychology, 6, 60-65.

19. SBA. (2018). Štúdia rodinného podnikania na Slovensku. http://www.sbagency.sk/sites/default/files/3_studia_rodinneho_podnikania_na_slovens ku.pdf

20. Sedliačiková, M., Moresová, M., Aláč, P., \& Drábek, J. (2021). How Do Behavioral Aspects Affect the Financil Decisions of Managers and the Competitiveness of Enterprises? Journal of Competitiveness, 13(2), 99-116.

21. Sedliačiková, M., Stroková, Z., Hitka, M., \& Nagyová, N. (2020). Employees versus implementing controlling to the business. Entrepreneurship and Sustainability Issue, 7(3), 1527-1540.

22. Sharma, A., \& Joshi, S. (2017). Green consumerism: overview and further research directions. International Journal of Process Management and Benchmarking (IJPMB), $7(2)$.

23. Szabó, A. (2012). Family business in Hungary. 10 $0^{\text {th }}$ International Conference on Management, Enterprise and Benchmarking, June 1-2, 2012, Budapest, Hungary. 
24. Wróblewska-Kazakin, A. (2012). Problemy decyzyjne w firmach rodzinnych na przykladzier średnie goprzedsiebirostva. Przedsiebiorczość i Zarzadzanie, 13, 129-142.

25. Zhou, L. (2014). Social responsibility and employees' organizational identification in Chinese family firms: Influence of family ownership and family commitment. Chinese Management Studies, 8(4), 683-703. 